\title{
Long-term outcomes of imatinib in patients with FIP1L1/ PDGFRA associated chronic eosinophilic leukemia: experience of a single center in China
}

\author{
Shi-Qiang Qu ${ }^{1,2}$, Tie-Jun Qin ${ }^{1}$, Ze-Feng $\mathrm{Xu}^{1,2}$, Yue Zhang ${ }^{1,2}$, Xiao-Fei $\mathrm{Ai}^{3}$, Bing $\mathrm{Li}^{1,2}$, \\ Hong-Li Zhang ${ }^{1}$, Li-Wei Fang ${ }^{1}$, Li-Juan Pan ${ }^{1}$, Nai-Bo Hu ${ }^{1}$, Zhi-Jian Xiao ${ }^{1,2}$ \\ ${ }^{1}$ MDS and MPN Centre, Institute of Hematology and Blood Diseases Hospital, Chinese Academy of Medical Sciences \& Peking \\ Union Medical College, Tianjin, China \\ ${ }^{2}$ State Key Laboratory of Experimental Hematology, Institute of Hematology and Blood Diseases Hospital, Chinese Academy \\ of Medical Sciences \& Peking Union Medical College, Tianjin, China \\ ${ }^{3}$ Molecular Diagnostic Laboratory, Institute of Hematology and Blood Diseases Hospital, Chinese Academy of Medical Sciences \\ \& Peking Union Medical College, Tianjin, China \\ Correspondence to: Zhijian Xiao, email: zjxiao@hotmail.com \\ Keywords: eosinophilia, FIPIL1-PDGFRA, chronic eosinophilic leukemia, imatinib \\ Received: February 23, $2016 \quad$ Accepted: April 03, $2016 \quad$ Published: April 21, 2016
}

\section{ABSTRACT}

Background: The FIP1L1/PDGFRA (F/P) fusion gene is the most common clonal genetic abnormality of chronic eosinophilic leukemia (CEL). Tyrosine kinase inhibitors (TKI), such as imatinib, have been demonstrated to be effective therapies for $F / P$ mutated disease. The aim of this study was to analyze the treatment response and long term prognosis in patients with F/P mutated CEL.

Methods: The clinical features and treatment responses of 33 consecutive patients with F/P mutated CEL between August 2006 and October 2014 were analyzed. The 33 cases received imatinib therapy at an initial dose of $100 \mathrm{mg} /$ day (30 patients) or 200 $\mathrm{mg} /$ day ( 3 patients); the maintenance dose depended on the response condition and patient willingness. Through the follow up, the molecular responses were regularly monitored.

Results: With a median follow up of 64 months, $94 \%$ of the 33 patients with F/P mutated CEL achieved a complete hematologic remission (CHR), and $97 \%$ achieved a complete molecular remission (CMR) after a median of 3 (1.5-12) months. Twentyfour cases received maintenance therapy, with a median CMR duration of 43 (588) months. Imatinib therapy was discontinued in 8 cases, including 4 cases who experienced relapse, and 4 patients who maintained CHR or CMR after discontinuing therapy with a median time of 47 (2-74) months. One case exhibited primary resistance with a PDGFRA T674I mutation.

Conclusions: F/P mutated CEL has an excellent long-term prognosis following imatinib therapy. A $100 \mathrm{mg}$ daily dose of imatinib is sufficient to induce remission, and a single $100 \mathrm{mg}$ weekly dose maintains a durable remission. A subgroup of patients may maintain a durable remission after discontinuing therapy with a CMR.

\section{INTRODUCTION}

FIP1L1/PDGFRA (F/P) rearrangement is the most common molecular abnormality in chronic eosinophilic leukemia (CEL). Two study groups $[1,2]$ in 2003 reported their independent discoveries of an $\mathrm{F} / \mathrm{P}$ fusion gene that results from a cryptic deletion on chromosome $4 q 12$ in patients with hypereosinophilic syndrome (HES); these patients were subsequently re-diagnosed with CEL. According to the specific molecular abnormality, the revised WHO classification in 2008 recognized the myeloid and lymphoid neoplasms with eosinophilia and abnormalities of platelet-derived growth factor receptor (PDGFR) A/B or fibroblast growth factor1 (FGFR1) as a new subgroup of myeloid neoplasms, which comprise three rare specific disease groups [3]. These 3 diseases 
result from a fusion gene that encodes an aberrant tyrosine kinase.

The tyrosine kinase inhibitor (TKI) Imatinib mesylate has revolutionized the therapy for PDGFRrelated disease [4-12]. F/P kinase activity is more sensitive to imatinib than BCR-ABL, and the occurrence of drug resistance is rare [5]. The therapeutic effects have been established from previous reports [4-12]; a low dose (100-200 mg/day) obtained an excellent response, and a lower dose (100-200 mg/week) effectively maintained remission. Nevertheless, the long term prognosis, drug withdrawal and drug resistance therapy remain unclear. In this study, we retrospectively analyzed the treatment response and long term prognosis of 33 Chinese patients with F/P mutated CEL.

\section{RESULTS}

\section{Patient characteristics}

The laboratory characteristics of the patients with F/P mutated CEL are shown in Table 1. At presentation, most patients had severe eosinophilia (AEC $\geq 5 \times 10^{9} / \mathrm{L}$ ) and a significantly increased serum vitamin B12 level. A significant proportion presented with anemia, thrombocytopenia, and myelofibrosis. The most frequent organ involvement of the $\mathrm{F} / \mathrm{P}$ mutated disease occurred in the spleen (68\%), lung (44\%), skin (28\%), liver (23\%), and heart $(22 \%)$. The constitutional symptoms, including fatigue, night swear, and weight loss, were frequent in the patients with F/P fusion. Thromboembolism was one of the most critical complications at presentation. One patient presented with thrombosis, and a digital subtraction angiography of the lower extremities for the left lower leg indicated a completely occluded thrombus of the left popliteal vein and collateral angiogenesis. Another patient presented with palpitation and dyspnea, and an echocardiography indicated a right ventricular mural thrombus.

\section{Treatment response}

The median disease history was 6 (1-127) months prior to receiving imatinib treatment, and the median time of imatinib treatment was 30 (2-99) months. Thirty-one patients (94\%) achieved a CHR, 1 patient achieved a PHR, and one patient had no hematological remission. The molecular response of the patients was evaluated regularly (Figure 1). Thirty-two patients (97\%) achieved a CMR after a median of 3 (1.5-12) months.

With a median follow-up of 46 (9-100) months, 24 patients who achieved a CMR remained on maintenance therapy. The imatinib maintenance dose was $100 \mathrm{mg} /$ day (patients 23 to 33), $100 \mathrm{mg} /$ week (patients 11 to 19), $100 \mathrm{mg}$ thrice weekly (patients 20 to 22), and $50 \mathrm{mg} /$ week (patient 10). Two patients experienced a hematologic relapse; these patients had maintenance doses of $100 \mathrm{mg} /$ week (patient 11) and $50 \mathrm{mg} /$ week (patient 10), respectively. Two patients with a $100 \mathrm{mg} /$ week dose remained in a CHR (patients 18 and 19) and were not monitored for fusion gene at the last contact. The remaining 20 patients remained in a CMR with a median duration of 43 (5-88) months.

\section{Cessation of imatinib mesylate}

Eight patients (patients 2 to 9) discontinued imatinib treatment after they acquired CMR because of a lack of compliance $(\mathrm{n}=7)$ and medical decisions for reproduction $(\mathrm{n}=1)$. Four patients (patients 2 to 5) experienced a hematologic relapse from 2 to 48 months after the discontinuation of imatinib. Two patients (patients 2 and 3) exhibited secondary imatinib resistance and altered other treatment. One patient (patient 4) died after relapse; however, the cause of death was unknown. One patient (patient 5) did not receive treatment because of the lack of symptoms. The other 4 patients (patients 6 to 9) remained in a CHR for a median of 47 months (range 2-74) after discontinuation; 2 patients (patients 7 and 9) maintained a $\mathrm{CMR}$, and the other 2 patients (patients 6 and 8) were not monitored for $\mathrm{F} / \mathrm{P}$ fusion gene for an interval of 3 months at the last contact (Table 2).

\section{Imatinib-resistant therapy}

Three patients (patients 1 to 3 ) exhibited imatinib resistance during the period of treatment (Table 3). One patient (patient 1) exhibited primary resistance with a PDGFRA T674I mutation; he subsequently received nilotinib treatment, but, unfortunately, a response was not achieved, and he died of cardiac complications. The other 2 patients exhibited secondary resistance 2 and 48 months after the discontinuation of imatinib. One patient (patient 3) was determined to have a T674I resistance mutation in the blast phase. He subsequently received imatinib $400 \mathrm{mg} /$ day, and a combined homoharringtonine plus cytarabine regiment was implemented as a salvage treatment; however, the disease still progressed, and he died of multiple organ failure 41 days after relapse. The remaining patient (patient 2) experienced a relapse 48 months after cessation of imatinib with a T674I resistance mutation, and he successively received high-dose imatinib, nilotinib, dasatinib and COP (Cyclophosphamide, Oncovin, and Prednisone) regiments; however, the salvage treatments were not successful, and he died of cardiac failure 17 months after the molecular relapse.

\section{Side effects of imatinib}

Imatinib was well tolerated with a low incidence of adverse events. Of the 33 cases, only 3 cases reported hematological toxicities, which were clearly associated with imatinib, and these events occurred at the initiation of therapy. One patient who was initially treated with a 
Table 1: F/P (+) CEL group characteristics

\begin{tabular}{|c|c|}
\hline Parameter & $\mathbf{F} / \mathbf{P}(+) \mathbf{C E L}$ \\
\hline Number of patients & 33 \\
\hline Male/Female(n) & $33 / 0$ \\
\hline Median age (range) (years) & $35(18-73)$ \\
\hline WBC $\left(\times 10^{9} / \mathrm{L}\right)($ range $)$ & $39.1(3.86-210)$ \\
\hline $\mathrm{WBC} \geq 30 \times 10^{9} / \mathrm{L}, \mathrm{n}(\%)$ & $15(44 \%)$ \\
\hline $\mathrm{Hb}(\mathrm{g} / \mathrm{L})($ range $)$ & $117.6(71-168)$ \\
\hline $\mathrm{Hb}<110 \mathrm{~g} / \mathrm{L}, \mathrm{n}(\%)$ & $12(35 \%)$ \\
\hline $\mathrm{BPC}\left(\times 10^{9} / \mathrm{L}\right)($ range $)$ & $137.5(16-422)$ \\
\hline $\mathrm{BPC}<100 \times 10^{9} / \mathrm{L}, \mathrm{n}(\%)$ & $11(33 \%)$ \\
\hline $\mathrm{AEC}\left(\times 10^{9} / \mathrm{L}\right)($ range $)$ & $17(1.6-78.8)$ \\
\hline $\mathrm{AEC} \geq 5 \times 10^{9} / \mathrm{L}, \mathrm{n}(\%)$ & $27(82 \%)$ \\
\hline Eosinophils in bone marrow(\%) & $36(8-69)$ \\
\hline Myelofibrosis (n) & $13 / 30$ \\
\hline Serum $\operatorname{IgE}(\mathrm{IU} / \mathrm{mL})($ range $)$ & $27.2(1-3660)$ \\
\hline $\operatorname{IgE}>N^{*}(n)$ & $2 / 22$ \\
\hline Serum B12(pmol/L) (range) & $2180(262-2959)$ \\
\hline Serum $B 12>N^{*}(n)$ & $13 / 19$ \\
\hline
\end{tabular}

WBC: white blood cell, Hb: hemoglobin, BPC: blood platelet count, AEC: absolute eosinophil count, IgE: immunoglobulin $\mathrm{E}$, * Normal ranges $(\mathrm{N}): \operatorname{IgE}<165.3 \mathrm{IU} / \mathrm{mL}$, vitamin $\mathrm{B} 12<800 \mathrm{pmol} / \mathrm{L}$.

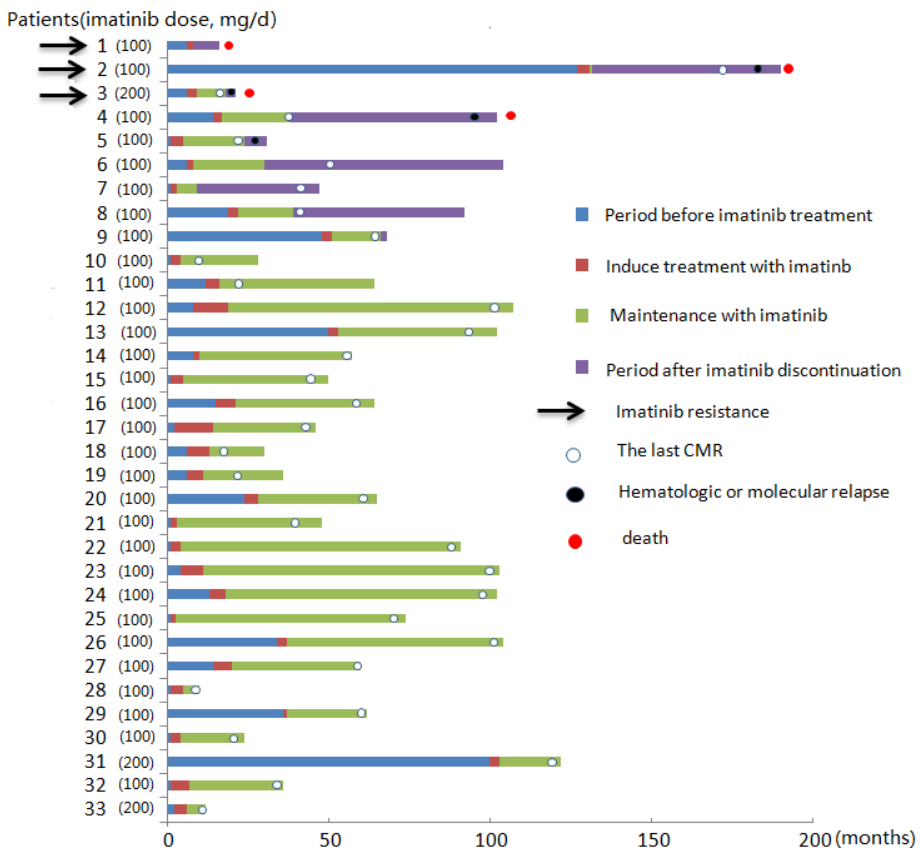

Figure 1: Imatinib therapeutic process and prognosis in patients with $\mathrm{F} / \mathrm{P}(+) \mathrm{CEL}$. 
Table 2: Outcome of imatinib discontinuation in 8 patients

\begin{tabular}{cccccc}
\hline Patient (No) & Age & Initial dose & Months to CMR & $\begin{array}{c}\text { Months of } \\
\text { treatment } \\
\text { duration }\end{array}$ & $\begin{array}{c}\text { Months of } \\
\text { imatinib } \\
\text { interruption }\end{array}$ \\
\hline $2^{*}$ & 43 & $100 \mathrm{mg} / \mathrm{d}$ & 4 & 4.5 & 48 \\
$3^{*}$ & 28 & $200 \mathrm{mg} / \mathrm{d}$ & 3 & 12 & 2 \\
$4^{*}$ & 38 & $100 \mathrm{mg} / \mathrm{d}$ & 3 & 24 & 12 \\
$5^{*}$ & 34 & $100 \mathrm{mg} / \mathrm{d}$ & 4 & 18 & 5 \\
6 & 73 & $100 \mathrm{mg} / \mathrm{d}$ & 2 & 24 & 74 \\
7 & 41 & $100 \mathrm{mg} / \mathrm{d}$ & 2 & 8 & 39 \\
8 & 32 & $100 \mathrm{mg} / \mathrm{d}$ & 3 & 20 & 55 \\
9 & 32 & $100 \mathrm{mg} / \mathrm{d}$ & 3 & 18 & 2 \\
\hline
\end{tabular}

* Hematologic relapse

Table 3: Clinical characteristics of the 3 patients with imatinib-resistance

\begin{tabular}{|c|c|c|c|}
\hline Patient (No) & Patient 1 & Patient 2 & Patient 3 \\
\hline Age & 57 & 43 & 28 \\
\hline Clinical manifestations & $\begin{array}{l}\text { fatigue, weight loss, bone } \\
\text { pain, splenomegaly }\end{array}$ & $\begin{array}{l}\text { night sweats, fatigue, } \\
\text { splenomegaly }\end{array}$ & $\begin{array}{l}\text { cough, bone pain, } \\
\text { splenomegaly }\end{array}$ \\
\hline $\mathrm{AEC}$ at first diagnosis & $7 \times 10^{9} / \mathrm{L}$ & $7 \times 10^{9} / \mathrm{L}$ & $4.32 \times 10^{9} / \mathrm{L}$ \\
\hline Initial karyotype & $47, \mathrm{XY},+8[12]$ & $46, X Y[15]$ & $46, X Y[20]$ \\
\hline Dose of imatinib (mg/day) & $100 \rightarrow 400$ & 100 & 200 \\
\hline $\begin{array}{l}\text { Time to imatinib resistance } \\
\text { (months) }\end{array}$ & primary resistance & 52.5 & 14 \\
\hline Mutation & T674I & T674I & T674I \\
\hline $\begin{array}{l}\text { Disease phase at diagnosis of } \\
\text { resistance }\end{array}$ & $\mathrm{CP}$ & $\mathrm{CP}$ & $\mathrm{BP}$ \\
\hline Therapy following resistance & $\begin{array}{l}\text { nilotinib(400 mg BID), } \\
\text { hydroxyurea(1g BID) }\end{array}$ & $\begin{array}{c}\text { imatinib }(100 \rightarrow 400 \mathrm{mg} / \\
\text { day), nilotinib(400 mg BID), } \\
\text { dasatinib(100 mg/day), } \\
\text { cyclophosphamide/oncovin/ } \\
\text { prednisone }\end{array}$ & $\begin{array}{c}\text { imatinib } 400 \mathrm{mg} / \mathrm{day}, \\
\text { homoharringtonine/ } \\
\text { cytarabine }\end{array}$ \\
\hline Follow up after resistance & death after 14 months & death after 17 months & death after 41 days \\
\hline
\end{tabular}

CP: chronic phase, BP: blast phase, BID: twice a day.

dose of $200 \mathrm{mg}$ /day suffered grade III neutropenia and thrombocytopenia and was subsequently managed by a temporary discontinuation of imatinib. The other 2 patients who received imatinib at a dose of $100 \mathrm{mg} /$ day suffered grade II neutropenia, and the neutrophil count recovered to normal with a decrease in the dose to $100 \mathrm{mg}$ every other day.

\section{Survival}

At the end of the follow up, 29 patients were alive, with a median follow-up of 64 (10-204) months, and the median survival did not reach significance. The 5-year OS was $93.5 \pm 4.4 \%$ (Figure 2). Four patients (patients 1 to 4) died at a median time of $60.5(20-204)$ months after presentation.

\section{DISCUSSION}

The clinical and laboratory features of 33 patients with $\mathrm{F} / \mathrm{P}$ mutated CEL were retrospectively reported. All 33 patients were male, and the specific reasons leading to this remain unknown. Eosinophil 
contributed to tissue remodeling and thrombosis via the release of eosinophil granules that contain major proteins and numerous cytokines [14]. The common clinical manifestations reported in the literature included cutaneous, pulmonary, gastrointestinal, cardiac, and neurological abnormalities [15]. Our data indicated the main characteristics of the patients with $\mathrm{F} / \mathrm{P}$ rearrangement included severe eosinophilia, substantially increased vitamin B12, splenomegaly, anemia, thrombocytopenia, and myelofibrosis. These features were in accordance with myeloproliferative neoplasms (MPN). In addition, the most frequent organ involvement was the spleen, followed by the lung, skin, liver, and heart. The cutaneous, pulmonary, and gastrointestinal symptoms were typically unspecific. The cardiac involvement presented with clear discomfort, and the most common damages included endomyocardial fibrosis and valvular abnormalities diagnosed via echocardiography and MRI. The neurological damage manifested as stroke and peripheral neuropathy. Moreover, thromboembolism should be a matter of vigilance, especially the extensive lower extremity venous thrombosis and pulmonary embolism. These serious complications typically require a multidisciplinary group of clinicians.

The benefit of imatinib in $\mathrm{F} / \mathrm{P}$ fusion gene positive CEL has since been confirmed in numerous studies, and imatinib is recommended as a clear first-line therapy in patients with F/P-positive CEL [7-11]. One hundred $\mathrm{mg}$ /day is sufficient to induce a CMR and histological response in most patients with an $\mathrm{F} / \mathrm{P}$ fusion gene, and 100-200 mg/week may be sufficient to maintain a durable remission in some patients. In this $33 \mathrm{~F} / \mathrm{P}$ fusion gene positive CEL patient cohort, most of whom received $100 \mathrm{mg} /$ day as the initial dose, thirty-two (97\%) patients achieved a CMR, and the median time was 3 months, which was shorter than the 12 months previously reported by Helbig et al [9] but similar to recent results from the Mayo clinic [16] and another French group [17]. This difference may be explained by a shorter period of daily imatinib treatment in the former study. In our study, most patients decreased the dose when a CMR was achieved; however, in Helbig et al, the dose was typically reduced at the time of a CHR. Our results also demonstrated that $100 \mathrm{mg} /$ week effectively maintains the response, which is consistent with other reports.

Limited information regarding the discontinuation of imatinib treatment for F/P fusion gene positive CEL has been reported. Although in-depth and durable molecular responses occur with imatinib, drug discontinuation may lead to relapse. One early study included 4 cases administered imatinib for a median of 9.5 months (range 7-14); all of the cases relapsed, and the median relapse time was 25.5 months (range 19-31) following imatinib discontinuation [10]. Recently, a group of French researchers reported 11 cases of discontinuation; 6 cases underwent a median imatinib treatment of 38.3 months (range 2-99), and relapse occurred from 1 to 27 months after discontinuation, whereas the remaining 5 cases received imatinib treatment for a median of 30.2 months (range 21.3-45.5) and maintained a CHR or CMR 31 months (range 9-88) after discontinuation [17]. In an isolated case report, 2 cases discontinued imatinib after a 5-year CMR duration and maintained a CMR 24 months after discontinuation [18]. In our group, 8 cases stopped oral imatinib after achieving a CMR; 4 cases discontinued imatinib with a median treatment of 17.5 months (range 4.5-24) and subsequently relapsed at a median follow up of 8.5 months (range 2-48), and 1 patient (patient 2) maintained a CMR duration of 48 months after discontinuation. The remaining 4 cases maintained a CHR or CMR 47 months (range 2-74) after discontinuation; these patients had received imatinib for a median of 19 months (range 8-24). Our findings suggested that some patients may maintain long-term remission following the termination of therapy at the CMR status; however, other patients require a long-term treatment to maintain a durable remission. To date, the specific reasons for this difference remain unknown; we are using exomic- and whole genome sequencing in our patients to identify biomarkers for imatinib termination in $\mathrm{F} / \mathrm{P}$ fusion gene positive CEL. At present, evidence indicates that cessation of imatinib make most remission patients lose CMR,

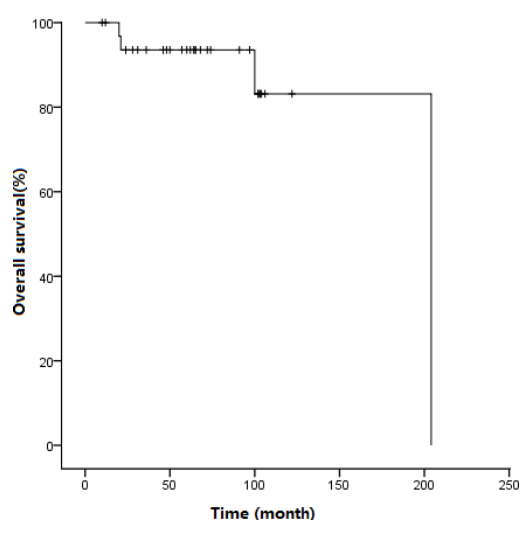

Figure 2: Survival curve for patients treated with imatinib. 
although a few patients acquire long-term remission after discontinuation, so we suggest imatinib treatment should be continued after achieving a CMR, and discontinuation be only used on perspective clinical trial. The patients who have withdrawn imatinib should monitor molecular changes closely, and restart imatinib treatment as soon as possible when fusion gene is detected again.

Evidence indicates that imatinib resistance has been a rare event in patients with $\mathrm{F} / \mathrm{P}$ fusion gene and is typically related to disease progression [19-23]. A T674I mutation in the ATP-binding region of PDGFRA was the most common imatinib-resistant mutation and frequently occurred in the acceleration or blast phase. Moreover, nilotinib and sorafenib had limited clinical activity in the T674I mutation. In our resistant cohorts, 3 patients were determined to have a T674I resistant mutation at the chronic and blast phases, respectively. One patient exhibited primary imatinib resistance in the chronic phase. The other 2 patients acquired imatinib resistance at relapse during the drug withdrawal period. Drug withdrawal may be a risk factor for imatinib resistance. All three patients died after drug resistance; however, a combination of chemotherapy regiments was used. Thus, hematopoietic stem cell transplantation should be the first choice for these patients for a longer survival. Moreover, Some novel TKIs like ponatinib [24] or HSP90 inhibitor [25] should be investigated to against T674I mutation in clinical.

In conclusion, the current findings demonstrated the overall clinical and laboratory features of Chinese patients with F/P mutated CEL and concurrently indicated the outcome of imatinib treatment. To the best of our knowledge, this series is the largest F/P mutated CEL dataset to date from Asia. In the TKI era, the prognosis of $\mathrm{F} / \mathrm{P}$ mutated CEL has been substantially improved. In our groups, the 5-year OS was $93.5 \%$, which was similar to a previous report in a western population [16]. In the future, the important issues include the identification of patients that may safely discontinue imatinib and how to overcome drug resistance.

\section{MATERIALS AND METHODS}

\section{Study population}

Thirty-three consecutive patients with F/P mutated CEL were diagnosed or re-diagnosed according to the 2008 revised WHO classification criteria [3]. The patients treated with imatinib between August 2006 and October 2014 in the Institute of Hematology and Blood Diseases Hospital, Chinese Academy of Medical Sciences (CAMS) and Peking Union Medical College (PUMC) were included in this study. All patients were male with a median age of 35 (18-73) years. This study protocol was approved by the Ethical Committee of the Institute of Hematology, CAMS and PUMC following the ethical principles of the Declaration of Helsinki.

\section{Baseline evaluation}

In general, a complete history and physical examination were carefully evaluated in all patients, and laboratory tests were performed at baseline, including a complete blood count, multiple stool ova and parasite testing, chemistries, serum total $\operatorname{IgE}$, vitamin B12, bone marrow (BM) morphology, conventional cytogenetics, F/P fusion gene (by nested polymerase chain reaction (PCR)), and $\mathrm{T}$ cell receptor (TCR) gene rearrangement PCR. Electrocardiogram, echocardiography, chest radiography, and abdominal ultrasound were also performed at baseline to determine organ involvement. Tissue biopsies were obtained when clinically indicated. The PDGFRA/B and FGFR1 rearrangement at baseline were analyzed via fluorescence in situ hybridization (FISH). More than grade 2 was recognized as myelofibrosis according to the European consensus on grading bone marrow fibrosis [13]. Splenomegaly and hepatomegaly were present when the organ could be touched below the rib edge. The normal values of serum $\mathrm{IgE}$ and vitamin B12 were $<165.3 \mathrm{IU} / \mathrm{mL}$ and $<800 \mathrm{pmol} / \mathrm{L}$, respectively.

\section{Detection of F/P fusion gene at diagnosis and for monitoring minimal residual disease}

RNA extraction from BM samples and cDNA synthesis were conducted using standard procedures after the isolation of mononuclear cells following red cell lysis. Nested RT-PCR for the detection of the F/P fusion gene was performed as previously described [1]. The following primers were used: FIP1L1-F1, 5' acctggtgctgatctttctgat; PDGFRA-R1, 5' tgagagcttgtttttcactgga; FIP1L1-F2, 5' aaagaggatacgaatgggacttg; and PDGFRA-R2, 5' gggaccggcttaatccatag. All amplifications were performed for 35 cycles at a $65^{\circ} \mathrm{C}$ annealing temperature.

\section{Treatment regimen and response assessment}

For the 33 patients, the initial dose was $100 \mathrm{mg} /$ day in 30 patients and $200 \mathrm{mg} /$ day in the remaining 3 patients. The maintenance dose depended on the response condition and patient willingness. A complete hematologic remission (CHR) was defined as a decrease in the absolute eosinophil count (AEC) to the normal range $\left(0-0.5 \times 10^{9} /\right.$ $\mathrm{L})$ with a normal hemoglobin $(\mathrm{Hb})$ value $(\geq 110 \mathrm{~g} / \mathrm{L})$ and blood platelet count (BPC) $\left(\geq 100 \times 10^{9} / \mathrm{L}\right)[15]$. Partial hematological remission (PHR) was defined as a decrease in the eosinophil count to less than $50 \%$ of the baseline value, but not in the normal range. No hematological remission (NR) was defined as a stable or increasing eosinophil count. Complete molecular remission (CMR) was defined as a negative nested RT-PCR for $\mathrm{F} / \mathrm{P}$ transcripts. The national cancer institute common terminology criterion for adverse events (NCICTCAE) version 3.0 was utilized for side effect grading. 


\section{Statistical analysis}

Nonparametric comparisons of group means were conducted using Mann-Whitney U tests. Proportions were compared using Chi-squared tests. The overall survival (OS) was analyzed using the Kaplan-Meier method, and the survival times were measured from the date of diagnosis to the date of death or loss during follow-up. A $P$-value less than 0.05 was set as the level of statistical significance. All analyses were performed using SPSS software (version 13.0; SPSS, Inc., Chicago, IL). Data were censored at August 20, 2015.

\section{ACKNOWLEDGMENTS}

This work was supported, in part, by National Natural Science Funds (No. 81530008, No.81370611, No. 81270585, and No.81470297) and the Program for Peking Union Scholars and Innovative Research Team.

\section{Author contributions}

Contribution: Z.J.X. designed the research, was the principal investigator, and took primary responsibility for the manuscript; S.Q.Q. and Z.J.X.: acquisition of data, analysis and interpretation of data, and drafting the manuscript; S.Q.Q., Z.F.X., T.J.Q., Y.Z., B.L., H.L.Z., L.W.F., L.J.P., N.B.H. and Z.J.X. recruited the patients.

\section{CONFLICTS OF INTEREST} interests.

The authors declare there are no competing financial

\section{REFERENCES}

1. Cools J, DeAngelo DJ, Gotlib J, Stover EH, Legare RD, Cortes J, Kutok J, Clark J, Galinsky I, Griffin JD, Cross NC, Tefferi A, Malone J, et al. A tyrosine kinase created by fusion of the PDGFRA and FIP1L1 genes as a therapeutic target of imatinib in idiopathic hypereosinophilic syndrome. N Engl J Med. 2003; 348:1201-1214.

2. Griffin JH, Leung J, Bruner RJ, Caligiuri MA, Briesewitz R. Discovery of a fusion kinase in EOL-1 cells and idiopathic hypereosinophilic syndrome. Proc Natl Acad Sci U S A. 2003; 100:7830-7835.

3. Swerdlow SH, Campo E, Harris NL, eds. World Health Organization Classification of Tumours of Haematopoietic and Lymphoid Tissues. Lyon (France): IARC; 2008.

4. Schaller JL, Burkland GA. Case report: rapid and complete control of idiopathic hypereosinophilia with imatinib mesylate. MedGenMed. 2001; 3:9.

5. Gleich GJ, Leiferman KM, Pardanani A, Tefferi A, Butterfield JH. Treatment of hypereosinophilic syndrome with imatinib mesilate. Lancet. 2002; 359:1577-1578.
6. Klion AD, Robyn J, Akin C, Noel P, Brown M, Law M, Metcalfe DD, Dunbar C, Nutman TB. Molecular remission and reversal of myelofibrosis in response to imatinib mesylate treatment in patients with the myeloproliferative variant of hypereosinophilic syndrome. Blood. 2004;103:473-478.

7. Baccarani M, Cilloni D, Rondoni M, Ottaviani E, Messa F, Merante S, Tiribelli M, Buccisano F, Testoni N, Gottardi E, de Vivo A, Giugliano E, Iacobucci I, et al. The efficacy of imatinib mesylate in patients with FIP1L1PDGFRalpha-positive hypereosinophilic syndrome. Results of a multicenter prospective study. Haematologica. 2007; 92:1173-1179.

8. Jovanovic JV, Score J, Waghorn K, Cilloni D, Gottardi E, Metzgeroth G, Erben P, Popp H, Walz C, Hochhaus A, Roche-Lestienne C, Preudhomme C, Solomon E, et al. Low-dose imatinib mesylate leads to rapid induction of major molecular responses and achievement of complete molecular remission in FIP1L1-PDGFRA-positive chronic eosinophilic leukemia. Blood. 2007; 109:4635-4640.

9. Helbig G, Stella-Hołowiecka B, Majewski M, Całbecka M, Gajkowska J, Klimkiewicz R, Moskwa A, Grzegorczyk J, Lewandowska M, Hołowiecki J. A single weekly dose of imatinib is sufficient to induce and maintain remission of chronic eosinophilic leukaemia in FIP1L1-PDGFRAexpressing patients. Br J Haematol. 2008; 141:200-204.

10. Klion AD, Robyn J, Maric I, Fu W, Schmid L, Lemery S, Noel P, Law MA, Hartsell M, Talar-Williams C, Fay MP, Dunbar CE, Nutman TB. Relapse following discontinuation of imatinib mesylate therapy for FIP1L1/PDGFRA-positive chronic eosinophilic leukemia:implications for optimal dosing. Blood. 2007; 110:3552-3556.

11. Metzgeroth G, Walz C, Erben P, Popp H, Schmitt-Graeff A, Haferlach C, Fabarius A, Schnittger S, Grimwade D, Cross NC, Hehlmann R, Hochhaus A, Reiter A. Safety and efficacy of imatinib in chronic eosinophilic leukaemia and hypereosinophilic syndrome: A phase-II study. Br J Haematol. 2008; 143:707-715.

12. David M, Cross NC, Burgstaller S, Chase A, Curtis C, Dang R, Gardembas M, Goldman JM, Grand F, Hughes G, Huguet F, Lavender L, McArthur GA, et al. Durable responses to imatinib in patients with PDGFRB fusion gene-positive and BCR-ABL-negative chronic myeloproliferative disorders. Blood. 2007; 109:61-64.

13. Thiele J, Kvasnicka HM, Facchetti F, Franco V, van der Walt J, Orazi A. European consensus on grading bone marrow fibrosis and assessment of cellularity. Haematologica. 2005; 90:1128-1132.

14. Rosenberg HF, Dyer KD, Foster PS. Eosinophils: changing perspectives in health and disease. Nat Rev Immunol. 2013;13:9-22.

15. Ogbogu PU, Bochner BS, Butterfield JH, Gleich GJ, HussMarp J, Kahn JE, Leiferman KM, Nutman TB, Pfab F, Ring J, Rothenberg ME, Roufosse F, Sajous MH, et al. Hypereosinophilic syndromes: a multicenter, retrospective 
analysis of clinical charatceristics and response to therapy. J Allergy Clin Immunol. 2009; 124:1319-1325.

16. Pardanani A, D’Souza A, Knudson RA, Hanson CA, Ketterling RP, Tefferi A. Long-term follow-up of FIP1L1PDGFRA-mutated patients with eosinophilia: survival and clinical outcome. Leukemia. 2012; 26:2439-2441.

17. Legrand F, Renneville A, Macintyre E, Mastrilli S, Ackermann F, Cayuela JM, Rousselot P, Schmidt-Tanguy A, Fain O, Michel M, de Jaureguiberry JP, Hatron PY, Cony-Makhoul P, et al; on behalf of the French Eosinophil Network. The Spectrum of FIP1L1-PDGFRA-Associated Chronic Eosinophilic Leukemia: New Insights Based on a Survey of 44 Cases. Medicine (Baltimore). 2013; [Epub ahead of print]

18. Helbig G, Kyrcz-Krzemień S. Cessation of imatinib mesylate may lead to sustained hematologic and molecular remission in FIP1L1-PDGFRA-mutated hypereosinophilic syndrome. Am J Hematol. 2014; 89:115.

19. Lierman E, Michaux L, Beullens E, Pierre P, Marynen P, Cools J, Vandenberghe P. FIP1L1-PDGFRalpha D842V, a novel panresistant mutant, emerging after treatment of FIP1L1-PDGFRalpha T674I eosinophilic leukemia with single agent sorafenib. Leukemia. 2009; 23:845-851.

20. Ohnishi H, Kandabashi K, Maeda Y, Kawamura M, Watanabe T. Chronic eosinophilic leukaemia with FIP1L1PDGFRA fusion and T6741 mutation that evolved from Langerhans cell histiocytosis with eosinophilia after chemotherapy. Br J Haematol. 2006; 134:547-549.
21. Score J, Walz C, Jovanovic JV, Jones AV, Waghorn K, Hidalgo-Curtis C, Lin F, Grimwade D, Grand F, Reiter A, Cross NC. Detection and molecular monitoring of FIP1L1PDGFRA-positive disease by analysis of patientspecific genomic DNA fusion junctions. Leukemia. 2009; 23:332-339.

22. von Bubnoff N, Sandherr M, Schlimok G, Andreesen R, Peschel C, Duyster J. Myeloid blast crisis evolving during imatinib treatment of an FIP1L1-PDGFR alphapositive chronic myeloproliferative disease with prominent eosinophilia. Leukemia. 2005; 19:286-287.

23. Metzgeroth G, Erben P, Martin H, Mousset S, Teichmann M, Walz C, Klippstein T, Hochhaus A, Cross NC, Hofmann WK, Reiter A. Limited clinical activity of nilotinib and sorafenib in FIP1L1-PDGFRA positive chronic eosinophilic leukemia with imatinib-resistant T674I mutation. Leukemia. 2012; 26:162-164.

24. Jin Y, Ding K, Li H, Xue M, Shi X, Wang C, Pan J. Ponatinib efficiently kills imatinib-resistant chronic eosinophilic leukemia cells harboring gatekeeper mutant T674I FIP1L1-PDGFR $\alpha$ : roles of Mcl-1 and $\beta$-catenin. Mol Cancer. 2014;13:17.

25. Demidenko ZN, An WG, Lee JT, Romanova LY, McCubrey JA, Blagosklonny MV. Kinase-addiction and bi-phasic sensitivity-resistance of Bcr-Abl- and Raf-1expressing cells to imatinib and geldanamycin. Cancer Biol Ther. 2005;4:484-490. 